\title{
Effect of pimobendan on exercise capacity in patients with heart failure: main results from the Pimobendan in Congestive Heart Failure (PICO) trial
}

\author{
The Pimobendan in Congestive Heart Failure (PICO) Investigators
}

\begin{abstract}
Primary objective-To determine the effects of pimobendan 2.5 and $5 \mathrm{mg}$ daily on exercise capacity in patients with chronic heart failure.

Design-A randomised, double blind, placebo controlled trial of the addition of pimobendan to conventional treatment with a minimum follow up of 24 weeks.

Setting-Outpatient cardiology clinics in six European countries.

Patients-317 patients with stable symptomatic heart failure, objectively impaired exercise capacity, and an ejection fraction of $45 \%$ or lower who were treated with at least an angiotensin converting enzyme inhibitor and a diuretic and who tolerated a test dose of pimobendan.

Results-Compared with placebo, both pimobendan 2.5 and $5 \mathrm{mg}$ daily improved exercise duration (bicycle ergometry) by $6 \%(P=0.03$ and 0.05$)$ after 24 weeks of treatment. At that time $63 \%$ of patients allocated to pimobendan and $59 \%$ of those allocated to placebo were alive and able to exercise to at least the same level as at entry $(P=0 \cdot 5)$. No significant effects on oxygen consumption (assessed in a subgroup of patients) and on quality of life (assessed by questionnaire) were observed. Pimobendan was well tolerated. Proarrhythmic effects (24-hour electrocardiography) were not observed. In both pimobendan groups combined the hazard of death was 1.8 (95\% confidence interval 0.9 to 3.5 ) times higher than in the placebo group.

Conclusions-Pimobendan improves exercise capacity in patients with chronic heart failure who are also on conventional treatment. The balance between benefit and risk of treatment with this compound remains to be established however.
\end{abstract}

(Heart 1996;76:223-231)

Keywords: pimobendan; heart failure; exercise capacity; clinical trials

Despite optimal treatment with diuretics and angiotensin converting enzyme inhibitors ${ }^{1}$ many patients with chronic heart failure suffer from persistent symptoms, limited exercise tolerance, and impaired quality of life. Also the prognosis continues to be poor. Hence, the treatment of this condition remains a therapeutic challenge.

Inotropic stimulation has met with little success. That digitalis glycosides improve exercise performance and quality of life is generally accepted but their effect upon mortality remains to be established. More recently phosphodiesterase inhibitors with both inotropic and vasodilating properties have been introduced. ${ }^{23}$ Much has been expected of this class of substances ${ }^{4}$ but long-term trials have shown that, although a moderate improvement in quality of life and exercise capacity can be achieved, mortality is increased. ${ }^{5-7} \mathrm{~A}$ novel approach to inotropic stimulation is the direct sensitisation of cardiac myofilaments to cytosolic calcium. Pimobendan (UDCG 115 BS) combines this effect with myocardial cyclic adenosine monophosphate dependent phosphodiesterase inhibition. ${ }^{8}$ It is rapidly absorbed, the peak plasma concentration is reached after 1.5 hours, and the effect lasts eight to 10 hours. Its main metabolite, UDCG 212 , has similar pharmacodynamic properties as the parent compound. In patients with heart failure, oral or intravenous pimobendan produces lasting and dose dependent beneficial haemodymic effects. Myocardial energetics seem to be favourably influenced because the ratio between cardiac work and oxygen consumption remains unchanged or is even improved. ${ }^{9}$ Systemic blood pressure is reduced slightly with higher doses of pimobendan. Although the phosphodiesterase inhibiting properties of pimobendan suggest arrhythmogenic potential, no important proarrhythmic effect has been observed in the clinical studies performed so far.

Several earlier trials in chronic heart failure patients showed beneficial effects when pimobendan was added to an optimal basic regimen with or without digitalis. ${ }^{10-12}$ Also, a trial comparing pimobendan with the angiotensin converting enzyme inhibitor enalapril was performed. ${ }^{13}$ To confirm these earlier findings, another placebo-controlled trial focusing on exercise capacity, oxygen consumption, and quality of life was undertaken with a longer (at least 24 weeks) treatment duration and in a larger group of patients than in previous trials.

Patients and methods

PATIENTS

In 30 centres (see Appendix) patients were recruited if they had chronic moderate (New 
Table 1 Exercise protocol (maximal bicycle ergometry in sitting position) and limits of exercise time allowed at entry

\begin{tabular}{|c|c|c|c|c|c|c|c|}
\hline \multirow[b]{2}{*}{$\begin{array}{l}\text { Men } \\
\text { Women }\end{array}$} & \multicolumn{7}{|c|}{ Age (years) } \\
\hline & $<65$ & $\begin{array}{l}65-69 \\
<50\end{array}$ & $\begin{array}{l}70-74 \\
50-59\end{array}$ & $60-64$ & $\begin{array}{l}\geqslant 75 \\
65-69\end{array}$ & $70-74$ & $\geqslant 75$ \\
\hline \multicolumn{8}{|l|}{ Workload (w): } \\
\hline 1st minute & 0 & 0 & 0 & 0 & 0 & 0 & 0 \\
\hline 2nd minute & 30 & 20 & 20 & 10 & 10 & 10 & 10 \\
\hline $\begin{array}{l}\text { Each next minute } \\
\text { Limits (min:s): }\end{array}$ & +10 & +10 & +10 & +10 & +10 & +10 & +10 \\
\hline \multicolumn{8}{|l|}{ Limits (min:s): } \\
\hline $\begin{array}{l}\text { At least } \\
\text { Less than }\end{array}$ & 3:00 & 3:00 & 3:00 & 3:00 & 3:00 & 3:00 & 3:00 \\
\hline Less than & $10: 00$ & $10: 00$ & $10: 00$ & $10: 00$ & 9:00 & $8: 00$ & 7:00 \\
\hline
\end{tabular}

York Heart Association class II-III) heart failure and had given written informed consent. All patients were at least 18 years of age, had been clinically stable without important changes in background medication for at least 30 days, and had an ejection fraction of $45 \%$ or lower. At two maximal exercise tests at least two weeks apart, exercise times were within the age and sex-specific limits shown in table 1 and no more than one minute apart.

Exclusion criteria were: stenotic, obstructive, or infectious cardiac disease; exercise capacity limited by angina; on waiting list for transplantation; suspicion of digitalis toxicity; acute myocardial infarction, coronary revascularisation, or episode of syncope or cardiac arrest during the last three months; automatic cardiac defibrillator implanted; primary renal or hepatic disease; haemodynamically significant pulmonary embolism or severe pulmonary disease; any other still present life-threatening condition; previous participation in a trial with pimobendan; and anticipated problems with follow up or compliance. Women were excluded unless they had been sterilised or were at least two years postmenopause. Baseline serum potassium had to be above $3.8 \mathrm{mmol} / \mathrm{l}$, serum creatinine below $194 \mu \mathrm{mol} / 1$, and aspartate aminotransferase below $100 \mathrm{U} / \mathrm{l}$.

The day before double blind medication was started, all patients were given a single test dose of pimobendan and were excluded if this dose produced significant symptoms or signs of intolerance.

\section{MEDICATION REGIMEN}

Background medication consisted of at least an angiotensin converting enzyme inhibitor and a diuretic. In addition, digitalis, nitrates, and molsidomine were allowed. Other inotropic agents, phosphodiesterase inhibitors, ibopamine, $\beta$ blockers, calcium antagonists, and other vasodilators could not be given. The only antiarrhythmic agent allowed was amiodarone, which had to have been started at least three months before entry. In patients receiving amiodarone, the QT interval corrected for heart rate ${ }^{14}(\mathrm{QTc})$ was monitored and the dose of this compound was reduced if QTc exceeded $480 \mathrm{~ms}$.

Double blind medication consisted of either placebo or pimobendan 2.5 or $5 \mathrm{mg}$ daily, divided in two equal doses. Allocation was randomised and blocked by centre. Medication was also taken on the days of exer- cise testing. Investigators were instructed to halve the dose when serum creatinine rose to at least $2.5 \mathrm{mg} / \mathrm{dl}(220 \mu \mathrm{mol} / \mathrm{l})$, or aspartate aminotransferase to at least $150 \mathrm{U} / 1$; and to withdraw double blind medication if such increase(s) persisted. Compliance was monitored by pill counts and was judged to have been good when at least $80 \%$ of the predicted number of double-blind medication capsules had been used without interruption for more than 48 hours.

\section{TRIAL DESIGN}

The screening phase consisted of a minimum of two outpatient clinic visits at least two weeks apart and was followed by a 24 week efficacy phase on double blind medication consisting of clinic visits after $2,4,8,12$, and 24 weeks. Clinical status permitting, all planned follow up assessments (including exercise testing) were completed irrespective of deviations from the double blind medication regimen (intention-to-treat principle). After completion of the efficacy phase, patients who were still alive at that moment were followed for further clinical events until a common stopping date. Patients who consented continued to take double blind medication (extended follow up phase).

The primary outcome was exercise time measured at least twice during screening, and 4,12 , and 24 weeks after the start of double blind medication. The same age and sex specific maximal bicycle ergometry protocol in the sitting position (table 1) was used in all centres. In a sub-study, gas exchange measurements were also performed.

Baseline ejection fraction was assessed by the investigator from a two dimensional echocardiogram, which was recorded on video tape and re-analysed later at the co-ordinating centre. If no analysable echocardiogram was available, a value obtained by another method was accepted. At each visit, the symptomatic state was assessed by the New York Heart Association classification. ${ }^{15}$ Quality of life was evaluated by the Minnesota Living with Heart Failure questionnaire ${ }^{16}$ administered twice during screening and after four, 12, and 24 weeks. Patient safety was assessed by monitoring vital signs (every visit), standard 12 lead electrocardiography preceding exercise testing, standard laboratory tests (screening, four, 12, and 24 weeks), and 24 hour electrocardiography (screening, four, and 24 weeks). ECGs were analysed at the co-ordinating centre. Proarrhythmia was assessed by criteria described previously. ${ }^{17}$

While the trial was ongoing, patients were withdrawn when a clinically relevant violation of the selection criteria was detected at the coordinating centre. The decision to do so was taken by the steering committee before the medication code was broken. Cause of death was classified by the critical events committee, which had no access to the medication code. Sudden death was defined as witnessed death within one hour of onset of symptoms or unexpected, unwitnessed death. ${ }^{18}{ }^{19}$ This committee also assessed whether missed exercise 
Table 2 Entry characteristics*

\begin{tabular}{|c|c|c|c|c|}
\hline \multirow[b]{2}{*}{ Characteristics } & \multirow[b]{2}{*}{ Placebo } & \multicolumn{2}{|c|}{ Pimobendan (daily dose) } & \multirow[b]{2}{*}{ Total } \\
\hline & & $2 \cdot 5 \mathrm{mg}$ & $5 \mathrm{mg}$ & \\
\hline Number of patients & $108(100 \%)$ & $106(100 \%)$ & $103(100 \%)$ & $317(100 \%)$ \\
\hline Age (years) & $65 \cdot 1(10 \cdot 3)$ & $64 \cdot 8(9 \cdot 1)$ & $66 \cdot 6(9 \cdot 1)$ & $65 \cdot 5(9 \cdot 5)$ \\
\hline Male & $79 \%$ & $78 \%$ & $83 \%$ & $80 \%$ \\
\hline \multicolumn{5}{|l|}{ History: } \\
\hline Ischaemic aetiology & $72 \%$ & $67 \%$ & $67 \%$ & $69 \%$ \\
\hline Documented MI & $65 \%$ & $63 \%$ & $57 \%$ & $62 \%$ \\
\hline Coronary bypass grafting & $18 \%$ & $26 \%$ & $21 \%$ & $22 \%$ \\
\hline Treated for high blood pressure & $23 \%$ & $36 \%$ & $20 \%$ & $26 \%$ \\
\hline Diabetes & $14 \%$ & $15 \%$ & $20 \%$ & $16 \%$ \\
\hline Median (range) duration of HF (months) & $34(1-225)$ & $35(2-480)$ & $35(2-284)$ & $35(1-480)$ \\
\hline Hospitalised $>24$ hours for $\mathrm{HF}$ & $73 \%$ & $66 \%$ & $70 \%$ & $70 \%$ \\
\hline NYHA II/III & $51 \% / 49 \%$ & $56 \% / 44 \%$ & $50 \% / 50 \%$ & $52 \% / 48 \%$ \\
\hline \multicolumn{5}{|l|}{ Basic regimen: } \\
\hline $\mathrm{ACE}$ inhibitor and diuretic & $100 \%$ & $100 \%$ & $100 \%$ & $100 \%$ \\
\hline Digitalis glycosides & $63 \%$ & $55 \%$ & $59 \%$ & $59 \%$ \\
\hline Nitrates & $43 \%$ & $44 \%$ & $46 \%$ & $\mathbf{4 4 \%}$ \\
\hline Molsidomine & $7 \%$ & $7 \%$ & $5 \%$ & $7 \%$ \\
\hline Amiodarone & $9 \%$ & $11 \%$ & $17 \%$ & $12 \%$ \\
\hline Anticoagulants & $56 \%$ & $46 \%$ & $51 \%$ & $51 \%$ \\
\hline \multicolumn{5}{|l|}{ Observations: } \\
\hline Regular sinus rhythm & $78 \%$ & $74 \%$ & $73 \%$ & $75 \%$ \\
\hline Ejection fraction $(\%) \dagger$ & $28(7)$ & $26(6)$ & $28(7)$ & $27(7)$ \\
\hline End diastolic volume $(\mathrm{ml}) \ddagger$ & $312(104)$ & $315(95)$ & $308(113)$ & $312(104)$ \\
\hline Exercise time (s) & $435(97)$ & $417(100)$ & $416(110)$ & $423(102)$ \\
\hline Drop of SBP during exercise & & $4 \%$ & $7 \%$ & $4 \%$ \\
\hline Total MLHF score & $27 \cdot 9(18 \cdot 4)$ & $26 \cdot 5(16 \cdot 8)$ & $25 \cdot 8(19 \cdot 1)$ & $26 \cdot 8(18 \cdot 1)$ \\
\hline QTc interval $>480 \mathrm{~ms}$ & $14 \%$ & $18 \%$ & $18 \%$ & $17 \%$ \\
\hline
\end{tabular}

${ }^{\star}$ Data are given either as a percentage or as a mean (SD); unless indicated otherwise. ACE, angiotensin converting enzyme; HF, heart failure; MI, myocardial infarction; MLHF, Minnesota Living with Heart Failure questionnaire; NYHA, New York Heart Association classification; SBP, systolic blood pressure; QTc, QT-interval corrected for heart rate.

†No entry value was available for one patient assigned to pimobendan $5 \mathrm{mg} /$ day (local values were accepted when central analysis was not possible).

$\ddagger$ No entry values were available for 11 patients assigned to placebo, 7 patients assigned to pimobendan $2.5 \mathrm{mg} /$ day and 10 patients assigned to pimobendan $5 \mathrm{mg} /$ day.

$\S$ No entry value was available for one patient assigned to pimobendan $2.5 \mathrm{mg} / \mathrm{day}$.

tests were due to the patient's cardiovascular condition.

\section{ETHICS}

The trial was carried out in accordance with the Declaration of Helsinki, ${ }^{20}$ had been approved by the institutional review board of each centre, and was monitored according to European Union standards of Good Clinical Practice. For patient safety, episodes of ventricular tachycardia in excess of three consecutive beats observed in centrally analysed 24 hour electrocardiograms were reported to the investigator. Data on serious adverse events were regularly reviewed by an independent monitoring committee, which was in the possession of the treatment code from the start of the trial onwards.

Table 3 Exercise testing and medication compliance during efficacy phase

\begin{tabular}{|c|c|c|c|c|}
\hline & \multirow[b]{2}{*}{ Placebo } & \multicolumn{2}{|c|}{ Pimobendan (daily dose) } & \multirow[b]{2}{*}{ Total } \\
\hline & & $2 \cdot 5 \mathrm{mg}$ & $5 \mathrm{mg}$ & \\
\hline Number of patients & 108 & 106 & 103 & 317 \\
\hline \multicolumn{5}{|l|}{ Exercise test done: } \\
\hline 4 weeks & 103 & 99 & 98 & 300 \\
\hline 12 weeks & 97 & 92 & 88 & 277 \\
\hline 24 weeks & 94 & 86 & 88 & 268 \\
\hline \multicolumn{5}{|c|}{ Exercise test done and good compliance: } \\
\hline 4 weeks & 101 & 97 & 94 & 292 \\
\hline 4 and 12 weeks & 93 & 82 & 82 & 257 \\
\hline 4,12 , and 24 weeks & 88 & 73 & 79 & 240 \\
\hline \multicolumn{5}{|c|}{ Exercise test not done due to death: } \\
\hline 4 weeks & 2 & 3 & 3 & 8 \\
\hline 12 weeks & 5 & 5 & 10 & 20 \\
\hline 24 weeks & 6 & 13 & 11 & 30 \\
\hline \multicolumn{5}{|c|}{ Exercise testing contraindicated: } \\
\hline 4 weeks & 1 & 3 & 2 & 6 \\
\hline 12 weeks & 3 & 4 & 4 & 11 \\
\hline 24 weeks & 4 & 2 & 3 & 9 \\
\hline \multicolumn{5}{|c|}{ Exercise test not done for other reasons: } \\
\hline 4 weeks & 2 & 1 & 0 & 3 \\
\hline 12 weeks & 3 & 5 & 1 & 9 \\
\hline 24 weeks & 4 & 5 & 1 & 10 \\
\hline
\end{tabular}

STATISTICAL METHODS

Sample size estimation was based on the results of an earlier trial with the same compound and the same primary outcome. ${ }^{11}$ For exercise time and for the physical dimension of the Minnesota Living with Heart Failure questionnaire, 70 patients per group were required for a power of $90 \%$ at a two-sided significance level of $5 \%$ (based on charts of the power function for analysis of variance tests ${ }^{21}$ and sums of squared treatment effects estimated from the earlier trial $\left.{ }^{11}\right)$. For peak oxygen consumption 45 patients per group were required. No interim analyses for efficacy were performed.

All patients who complied with the selection criteria and had started double blind medication were included in intention-to-treat analyses; no patient was excluded for protocol violations which had occurred during follow up. The primary pre-specified analysis of exercise time was limited to those patients who had at least the first follow up (four week) exercise test carried out and had shown good compliance (see medication regimen) up to the day of the test. If subsequent tests were not performed, whatever the reason, or were performed although compliance between tests had been poor, the last exercise time value obtained while compliance was good was carried forward. Tests of significance were performed by fixed-effects analysis of variance for repeated measurements. ${ }^{22}$ All $P$ values quoted are two-sided.

As a secondary analysis, changes in exercise time at 24 weeks were ranked and all patients assigned to placebo were compared by a standard non-parametric test with all patients assigned to pimobendan on an intention-totreat basis. If the patient had died or if there 
had been a cardiovascular contraindication for exercise testing, the rank assigned was that below the patient with the lowest rank based on exercise time changes actually observed. If exercise time was missing for other reasons, the last available value was carried forward in calculating the rank.

Percentages were compared between groups by chi-squared tests with one or two degrees of freedom for comparisons between two or three groups respectively. Hazards of all-cause mortality and of the combined event death or hospital admission for cardiovascular reasons were calculated by dividing the total number of events that had occurred by the number of person-years of follow up that patients had been at risk of the event considered. The time of first intake of double-blind medication was regarded as the beginning of follow up, and the day the patient was last known to be alive, as the end. Medication groups were compared by hazard ratios and their $95 \%$ confidence intervals. ${ }^{23}$ To assess whether the hazard ratio estimates for the combined endpoint of death or hospital admission for cardiovascular reasons were distorted by imbalance between treatment groups for clinical predictors of this event at baseline, the same hazard ratios were also estimated by Cox multivariate proportional hazard analysis. ${ }^{24}$
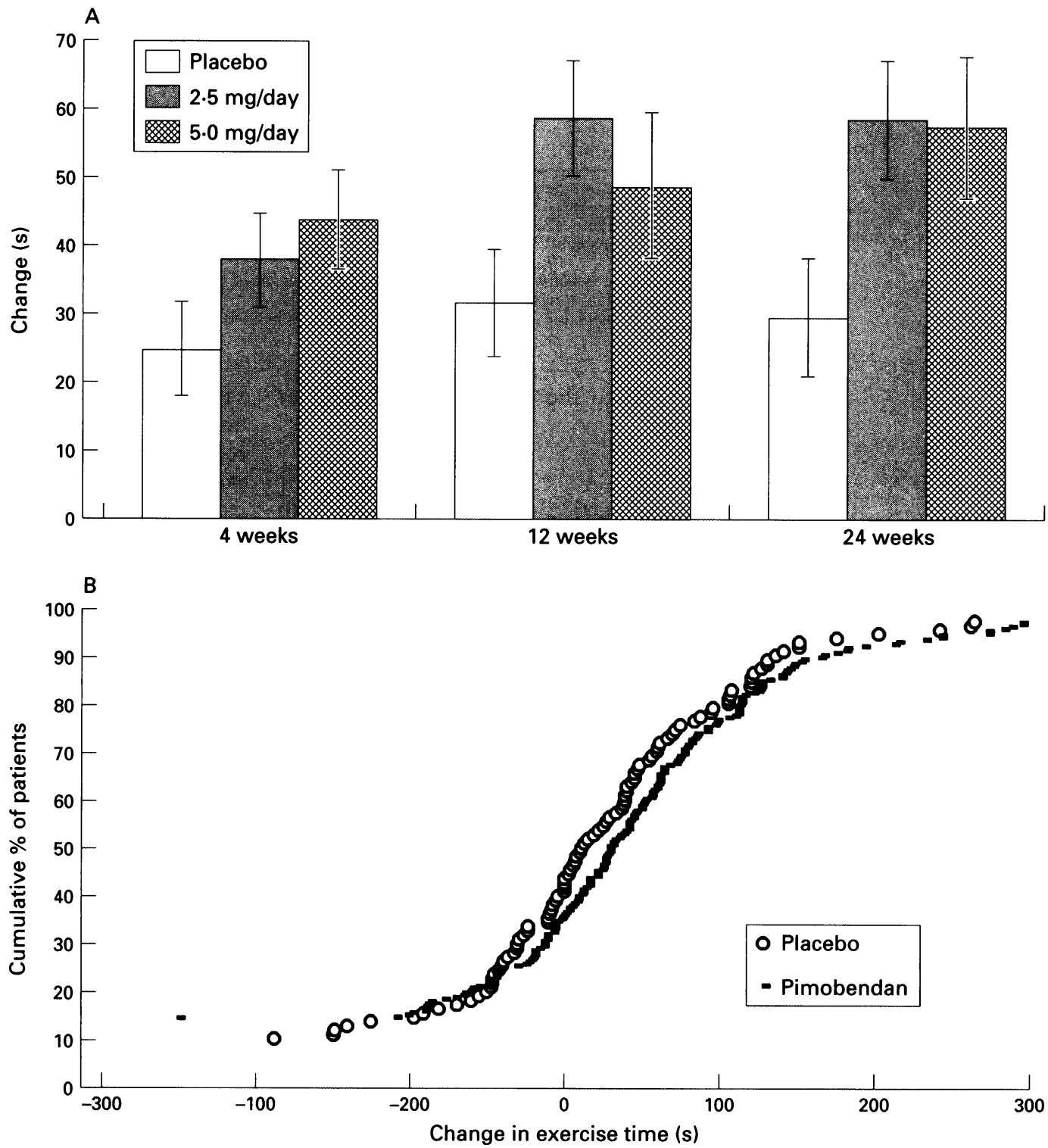

(A) Mean (SEM) of change in exercise time after four, 12 and 24 weeks relative to baseline (per protocol analysis) in 292 patients entered in the primary analysis (101 placebo, 97 pimobendan $2.5 \mathrm{mg} /$ day, and $945 \mathrm{mg} /$ day; table 3 ). The last available value was carried forward when data for 12 or 24 weeks was missing. For the 101 patients on placebo in this analysis, the mean entry exercise time was 437 seconds and the mean changes were: +25 (7) after four weeks, $+32(8)$ after 12 weeks, and +30 (9) seconds after 24 weeks. In the pimobendan $2 \cdot 5 \mathrm{mg} /$ day group the mean changes were $+38(7)$, $+59(8)$, and +59 (9) and in the $5 \mathrm{mg} /$ day group $+44(7),+49(11)$, and $+58(10)$ seconds respectively (overall $P$ $=0.06 ; 2.5 \mathrm{mg} /$ day versus $5 \mathrm{mg} /$ day $P=0.9 ; 2.5 \mathrm{mg} /$ day versus placebo $P=0.03,5 \mathrm{mg} /$ day versus placebo $P=0.05$; all pimobendan versus placebo $P=0.02$ ).

(B) Cumulative distributions of changes in exercise time at 24 weeks based on intention-to-treat for placebo (108 patients) and for both pimobendan groups combined (209 patients). In ten cases in the former group $(6+4$, table 3 ) and 29 in the latter group $(13+11+2+3 ;$ table $3, P=0 \cdot 2)$ the 24-week exercise test was missing because of death or a cardiovascular contraindication to exercise testing. Hence, for placebo the curve starts at the $10 \cdot 2$ th (11/108) and for pimobendan at the 14.4th (30/209) percentile. Whenever the 24-week test was missing for other reasons (4 placebo, $5+1$ pimobendan; table 3), the last available value was carried forward. The medians do not differ significantly (difference between medians $=18$ seconds, $P=0.5$ ) but in this trial patients assigned to pimobendan showed more improvement in exercise time than patients assigned to placebo, despite their higher incidence of death or contra-indications to exercise testing. 
Table 4 Clinical events (excluding extended follow up)

\begin{tabular}{|c|c|c|c|c|c|c|}
\hline \multirow[b]{2}{*}{ Event } & \multicolumn{3}{|c|}{ Number of patients with event ${ }^{*}$} & \multicolumn{3}{|c|}{ Ranked clinical outcome at 24 weekst } \\
\hline & $\begin{array}{l}\text { Placebo } \\
(n=108)\end{array}$ & $\begin{array}{l}\text { Pimobendan } \\
2 \cdot 5 m g / \text { day } \\
(n=106)\end{array}$ & $\begin{array}{l}\text { Pimobendan } \\
5 \text { mg/day } \\
(n=103)\end{array}$ & $\begin{array}{l}\text { Placebo } \\
(n=108)\end{array}$ & $\begin{array}{l}\text { Pimobendan } \\
2.5 \text { mg/day } \\
(n=106)\end{array}$ & $\begin{array}{l}\text { Pimobendan } \\
5 \text { mg/day } \\
(n=103)\end{array}$ \\
\hline Death (all causes) & 6 & 13 & 11 & 6 & 13 & 11 \\
\hline Acute myocardial infarction & 2 & 1 & 1 & 1 & 0 & 1 \\
\hline $\begin{array}{l}\text { Admission to hospital for } \\
\text { worsening heart failure } \ddagger\end{array}$ & 0 & 1 & 4 & 0 & 1 & 2 \\
\hline $\begin{array}{l}\text { Admission to hospital for } \\
\text { arrhythmia } \oint^{-} \\
\text {Admission to hospital for }\end{array}$ & 4 & 3 & 5 & 3 & 1 & 5 \\
\hline $\begin{array}{l}\text { Admission to hospital for } \\
\text { other cardiovascular reasons } \\
\text { Medication for heart failure }\end{array}$ & 14 & 17 & 16 & 8 & 10 & 5 \\
\hline added or increased\| & 29 & 25 & 22 & 17 & 12 & 10 \\
\hline $\begin{array}{l}\text { Anti arrhythmic agents added } \\
\text { Other cardiac medication }\end{array}$ & 6 & 7 & 6 & 1 & 3 & 0 \\
\hline $\begin{array}{l}\text { added or increased } \pi \\
\text { Double-blind medication }\end{array}$ & 3 & 5 & 0 & 1 & 0 & 0 \\
\hline $\begin{array}{l}\text { stopped by physician } \\
\text { Double-blind medication }\end{array}$ & 11 & 21 & 16 & 5 & 5 & 2 \\
\hline $\begin{array}{l}\text { reduced by physician } \\
\text { Admission to hospital for }\end{array}$ & 8 & 13 & 13 & 4 & 5 & 7 \\
\hline $\begin{array}{l}\text { non-cardiovascular reasons } \\
\text { None of the above }\end{array}$ & 12 & 13 & 18 & $\begin{array}{r}3 \\
50\end{array}$ & $\begin{array}{r}1 \\
55\end{array}$ & 4 \\
\hline
\end{tabular}

${ }^{\star}$ Each patient with at least one of the events listed counted.

†Each patient counted once and assigned to the uppermost applicable event listed.

$\ddagger$ In-hospital addition of intravenous inotropics (including digitalis).

SIn-hospital addition of an anti arrhythmic agent (including digitalis)

|Diuretics, ACE inhibitors, intravenous inotropics, digitalis, nitrates, or molsidomine added or increased at any time.

$\pi$ Calcium antagonists, $\beta$ blockers, or other vasodilators added or increased at any time.

${ }_{\star \star \star}$ Except admission to hospital for procedures already planned before entry.

\section{Results}

PATIENTS, CONDUCT, AND COMPLIANCE

The trial was completed as planned. From March 1993 to June 1994, 333 patients completed the screening phase and had one test dose of pimobendan administered. None of these patients showed acute intolerance but two were subsequently excluded (one for hypokalaemia, one for worsening heart failure). Thus 331 patients were started on double-blind medication. Before the medication code was broken 14 of these were excluded for violations of the selection criteria (four placebo, six pimobendan $2.5 \mathrm{mg} /$ day, four pimobendan $5 \mathrm{mg} /$ day; one excluded patient assigned to placebo died nine months after randomisation). Hence, 317 patients (108 allocated to placebo, 106 to pimobendan $2 \cdot 5$ $\mathrm{mg} /$ day, and 103 to $5 \mathrm{mg} /$ day) are the basis of this report. All but one had been followed until November 1994 for clinical events. Selected entry characteristics are presented in table 2 . Given the relatively small numbers in each treatment arm, randomisation resulted in well balanced groups.

Table 5 Mortality and mortality or first hospital admission for cardiovascular reasons (intention-to-treat; including extended follow up)

\begin{tabular}{|c|c|c|c|c|c|}
\hline & $\begin{array}{l}\text { Placebo } \\
(n=108)\end{array}$ & $\begin{array}{l}\text { Pimobendan } \\
2 \cdot 5 \text { mg/day } \\
(n=106)\end{array}$ & $\begin{array}{l}\text { HR } 2 \cdot 5 / \\
\text { placebo* } \\
(95 \% \text { CI) }\end{array}$ & $\begin{array}{l}\text { Pimobendan } \\
5 \text { mg/day } \\
(n=103)\end{array}$ & $\begin{array}{l}\text { HR 5I } \\
\text { placebo* } \\
(95 \% \text { CI) }\end{array}$ \\
\hline Deaths (all causes): & 11 & 20 & - & 16 & - \\
\hline Sudden cardiact & 7 & 15 & - & 7 & - \\
\hline Other cardiovasculart & 3 & 5 & - & 6 & - \\
\hline Non-cardiovasculart & 1 & - & - & 1 & - \\
\hline Unknown & - & - & - & 2 & - \\
\hline Hazard $\ddagger$ (per 100 & & & & & \\
\hline person-years) & $10 \cdot 8$ & $21 \cdot 3$ & $\begin{array}{l}2 \cdot 0 \\
(0.9 \text { to } 4 \cdot 1)\end{array}$ & $17 \cdot 4$ & $\begin{array}{l}1.6 \\
(0.7 \text { to } 3.4)\end{array}$ \\
\hline $\begin{array}{l}\text { No of deaths or } 1 \text { st } \\
\text { admission to hospital } \\
\text { Hazard } \ddagger \text { (per } 100\end{array}$ & 27 & 40 & - & 33 & - \\
\hline person-years) & $29 \cdot 5$ & $48 \cdot 5$ & $\begin{array}{l}1 \cdot 6 \\
(1 \cdot 0 \text { to } 2 \cdot 7)\end{array}$ & $41 \cdot 2$ & $\begin{array}{l}1 \cdot 4 \\
(0 \cdot 8 \text { to } 2 \cdot 3)\end{array}$ \\
\hline
\end{tabular}

*Hazard ratios (HR) comparing patients assigned to pimobendan $2.5 \mathrm{mg} /$ day and to pimobendan $5 \mathrm{mg} /$ day respectively with patients assigned to placebo; with $95 \%$ confidence intervals $(\mathrm{CI})$.

†As assessed by the Critical Events Committee.

ANumber of events divided by person-time of follow up until event or until end of extended follow up.
Table 3 summarises the extent to which exercise testing was performed in relation to compliance with the double-blind medication regimen. For the primary analysis of exercise time $92 \%$ of patients $(292 / 317)$ were available. In $76 \%(240 / 317)$ all three exercise tests were performed and compliance was good throughout the efficacy phase. One or more exercise test results was carried forward in the primary analysis for 52 patients. In 10 patients there was a reason other than death or a contra-indication for not performing the planned 24 week exercise test. For these the last exercise test result was carried forward in the ranked secondary analysis of change in exercise capacity at 24 weeks (see statistical methods).

Based on the same criteria for inclusion as for the primary analysis of exercise time, 35 patients on placebo, 34 on pimobendan $2.5 \mathrm{mg} /$ day, and $34 \mathrm{on}$ pimobendan $5 \mathrm{mg} /$ day respectively were available for analysis of gas exchange measurements. Similarly, 103 patients on placebo, 100 on pimobendan $2.5 \mathrm{mg} /$ day, and 94 on pimobendan $5 \mathrm{mg} /$ day were available for a per-protocol analysis of Minnesota Living with Heart Failure questionnaire scores.

\section{EXERCISE CAPACITY AND PEAK OXYGEN CONSUMPTION}

The mean changes in exercise time (relative to the last baseline test) for the patients included in the primary analysis are shown in figure (A). After four, 12, and 24 weeks respectively, the mean treatment effects of pimobendan $2.5 \mathrm{mg} /$ day relative to placebo were 13,27 , and 29 seconds $(P=0.03)$; and of pimobendan $5 \mathrm{mg} /$ day 19,17 , and 28 seconds $(P=$ $0.05)$.

Figure (B) shows the cumulative distributions of changes in exercise time at 24 weeks for the 108 patients assigned to placebo and the 209 patients assigned to pimobendan (both dose groups combined), based on inten- 
tion-to-treat and taking into account exercise tests which were not possible because of death or a contraindication. Of the 209 patients assigned to pimobendan, $63 \%$ were able to exercise at 24 weeks to at least the same level as at entry. Among the 108 patients assigned to placebo, this was the case in $59 \%(P=0.5$, non-parametric test).

In the subgroup of 35 patients allocated to placebo who had gas exchange measurements the mean peak oxygen consumption was $13 \cdot 1$ $\mathrm{ml} / \mathrm{min} . \mathrm{kg}$ at entry; and $13 \cdot 7,13 \cdot 3$, and 13.9 $\mathrm{ml} / \mathrm{min} . \mathrm{kg}$ after four, 12 , and 24 weeks respectively. At these time points, the mean effects of pimobendan $2.5 \mathrm{mg}$ /day (relative to placebo, per-protocol analysis) on this variable were $0.2,0.8$, and $0.4(P=0.4)$ and of pimobendan $5 \mathrm{mg} /$ day $0.6,0.8$, and $0.3 \mathrm{ml} / \mathrm{min} . \mathrm{kg}$ respectively $(P=0 \cdot 4)$.

\section{NEW YORK HEART ASSOCIATION CLASS AND QUALITY OF LIFE}

Of those assigned to placebo, $4 \%$ (4/108) were in a better New York Heart Association class at least once during follow up than at entry and never worsened or died before the 24 week visit. The corresponding figure for those assigned to pimobendan was $10 \%(20 / 209 ; \mathrm{P}$ $=0.06$ ).

For the 103 patients on placebo analysed for Minnesota Living with Heart Failure questionnaire scores, the mean total score at entry was $27 \cdot 7$ units; and $25 \cdot 0,25 \cdot 6$, and $26 \cdot 1$ units after four, 12 and 24 weeks respectively. At these time points, the mean effects of pimobendan $2.5 \mathrm{mg}$ /day (relative to placebo, per-protocol analysis) were $-0.4,-1 \cdot 6$, and $-1.2(P=0.5)$ units and of pimobendan 5 $\mathrm{mg} /$ day $-0 \cdot 0,+0 \cdot 7$, and $-1 \cdot 0$ units respectively $(P=0 \cdot 9)$.

\section{CLINICAL OUTCOME}

During the efficacy phase proarrhythmia based on 24-hour electrocardiography was observed in 20 patients assigned to placebo, 15 to pimobendan $2.5 \mathrm{mg} /$ day, and 14 to pimobendan $5 \mathrm{mg} /$ day. When sudden cardiac death was regarded as proarrhythmia also, these numbers became 24,22 , and 19 respectively $(P=0.5)$.

Data on the clinical outcome at the end of the efficacy phase (that is, at 24 weeks) is given in table 4. Double-blind medication was stopped or reduced significantly more often in patients allocated to pimobendan than to placebo $(11+8=19$ placebo, $21+13=34$ pimobendan $2.5 \mathrm{mg} /$ day, $16+13=29$ pimobendan $5 \mathrm{mg}$ /day; $\mathrm{P}=0.04$ ).

Data on mortality and hospital admission for cardiovascular reasons during the entire trial (that is, efficacy and extended follow up phase combined) based on intention-to-treat are given in table 5 . The mean follow up was 11 months and $44 \%$ of patients were followed for at least one year. In total, 47 patients died. While taking double-blind medication, eight died on placebo, 14 on pimobendan $2.5 \mathrm{mg} /$ day and 11 on pimobendan $5 \mathrm{mg} /$ day. The causes of death are also given in table 5 . More than half of all deaths were classified as sudden. Cardiovascular deaths were caused by myocardial infarction (one in each treatment group), worsening heart failure (one placebo, two pimobendan $2.5 \mathrm{mg} /$ day, and five pimobendan $5 \mathrm{mg} /$ day), multiple organ failure (one placebo), cerebrovascular accident (one pimobendan $2.5 \mathrm{mg} /$ day), and peripheral vascular disease (one pimobendan $2.5 \mathrm{mg}$ /day). The two non-cardiac deaths were caused by bladder cancer (placebo) and pneumonia (pimobendan $5 \mathrm{mg} /$ day).

Although there was a trend towards a higher mortality hazard among patients allocated to pimobendan, neither comparison with placebo was statistically significant at the $5 \%$ level (each $95 \%$ confidence interval includes one, table 5). In both pimobendan groups combined, the mortality was 1.8 times higher $(0.9$ to 3.5 ) than in the placebo group. Similarly, there was a non-significant trend towards higher hazards of the combined event death or first hospital admission for cardiovascular reasons.

The adjusted estimates from the Cox regression model of the hazard ratios for death or hospital admission for cardiovascular reasons were 1.5 comparing pimobendan $2.5 \mathrm{mg} /$ day with placebo (95\% confidence interval 0.9 to 2.5$)$ and $1.2(0.7$ to $2 \cdot 1)$ comparing pimobendan $5 \mathrm{mg} /$ day with placebo. Conditionally independent and significant $(P<0.05)$ covariates associated with a reduced risk in the Cox model were (hazard ratios between brackets): change of systolic blood pressure during exercise $(0.983 / \mathrm{mm} \mathrm{Hg}$ rise), resting systolic blood pressure $(0.980 / \mathrm{mm} \mathrm{Hg})$, exercise time $(0.998 / \mathrm{s})$, and previous coronary bypass grafting $(0 \cdot 5)$. Covariates associated with an increased risk were previous hospital admission for heart failure $(2 \cdot 6)$, history of symptomatic arrhythmia (1.6) and history of high blood pressure treated with drugs $(1 \cdot 7)$. The adjusted estimates are similar to those given in table 5 . Conditional on the covariates mentioned, age, sex, NYHA class, ejection fraction, and use of digitalis were not associated with the risk.

\section{Discussion}

The main finding of this trial confirms earlier findings that pimobendan improves exercise capacity..$^{10-12}$ Relative to placebo, the magnitude of this effect seemed to increase until 12 weeks of treatment and then to persist at the same level at 24 weeks (figure A). This is not only the largest placebo-controlled trial to date but also the first one with a treatment period of this duration. This sustained effect has therefore not been reported before.

The largest earlier placebo-controlled trial studied 198 patients in NYHA class III who were treated for 12 weeks with either placebo, or 2.5 , or 5 , or $10 \mathrm{mg} /$ day of pimobendan. ${ }^{11}$ Mean exercise duration increases (rounded to whole seconds) of $30,68,122$, and 81 respectively were observed. Adding these mean increases to the mean entry exercise time in the placebo group (536 seconds) yields mean follow up exercise durations of $566,604,658$, 
and 617 seconds respectively for placebo or 2.5 , or 5 , or $10 \mathrm{mg} /$ day of pimobendan. Hence, in that trial the effect of treatment expressed as the percentage difference compared with placebo was $((604-566) \times$ 100) $/ 566$ or $7 \%$ for treatment with $2.5 \mathrm{mg} /$ day of pimobendan. Calculated in the same way, the treatment effects for 5 and for $10 \mathrm{mg} /$ day of pimobendan were $16 \%$ and $9 \%$ respectively. In another smaller earlier trial, ${ }^{10}$ in which treatment effects were calculated in a similar manner results of $16 \%$ and $13 \%$ for 5 and $10 \mathrm{mg} /$ day of pimobendan respectively were observed.

Based on the data given in table 2 and figure (A) and by the same method of calculation, treatment effects at 24 weeks in this trial were $6 \%$ for 2.5 and also $6 \%$ for $5 \mathrm{mg}$ /day of pimobendan. Thus the magnitude of the effect of $2.5 \mathrm{mg} /$ day of pimobendan in this trial was similar to that in the largest earlier trial ${ }^{11}$ but the effect of $5 \mathrm{mg} /$ day was considerably less than observed before. ${ }^{1011}$ Because of the doseresponse relations observed in these earlier trials, the $10 \mathrm{mg} /$ day dose was not studied in this trial. Contrary to the largest earlier trial, ${ }^{11}$ no difference was observed between the 2.5 and $5 \mathrm{mg} /$ day dosages with respect to their effect on exercise duration. One can only speculate why the effect on exercise duration of the $5 \mathrm{mg} /$ day dose in this trial was less marked than observed earlier. In the largest earlier trial, ${ }^{11}$ all patients were in NYHA class III. In the present trial that was the case in $48 \%$ (table 2). We found no relation between the effect of pimobendan and NYHA class at entry. Hence, it seems unlikely that this can explain the difference between this and the earlier result. Similarly, it is unlikely that the difference in angiotensin converting enzyme inhibitor use $(80 \%$ in the largest earlier trial, all patients in the present one) or digitalis use $(88 \%$ in the largest earlier trial, $59 \%$ in the present one) can explain the difference. Whether there is a relation between the use of angiotensin converting enzyme inhibitors and the effect of pimobendan is not known and in our data there was no relation between the effect of pimobendan and use of digitalis. A factor may have been that patients in this trial were older than in the earlier trial $(65.5$ mean age in this one, 61 in the largest earlier trial) and that ischaemic heart disease was a more frequent aetiology (69\% in this trial and $44 \%$ in the largest earlier trial). This, and the different exercise methodology used, ${ }^{25}$ may have influenced the results. Alternatively, the larger efficacy of pimobendan $5 \mathrm{mg} /$ day relative to 2.5 and $10 \mathrm{mg} /$ day in the largest earlier trial ${ }^{11}$ may to a certain extent have been a chance finding. An argument in favour of this is that the $10 \mathrm{mg}$ dose has produced the largest haemodynamic improvement. ${ }^{10}$ In any case, this trial together with earlier trials ${ }^{10}{ }^{11}$ suggests that the therapeutic range of pimobendan is 2.5 to $5 \mathrm{mg} /$ day.

This trial did not reproduce the statistically significant effects of pimobendan on peak oxygen consumption ${ }^{1011}$ and on the Minnesota Living with Heart Failure questionnaire ${ }^{11}$ scores seen in earlier trials. Again, one can only speculate about the reasons. Peak oxygen consumption was measured only in a subgroup of patients and the power may have been insufficient. The Minnesota Living with Heart Failure questionnaire may be less sensitive to changes in patient wellbeing and/or less reproducible when used in different cultural settings than the one for which it was originally developed and validated.

This trial followed a classic pattern for exercise capacity trials in heart failure. Several additional design features, however, allowed us to clarify further the efficacy and safety of adding pimobendan to the prevailing basic heart failure regimen. As in the largest earlier trial, ${ }^{11}$ we randomised only those patients who tolerated a test dose of pimobendan. No patient was excluded because of acute intolerance. In fact, the present data show that pimobendan in the dosages studied is well tolerated. The number of patients in whom treatment had to be discontinued was small (table 4). No clinically relevant signs of proarrhythmia were observed. The number of patients in whom proarrhythmia was observed by 24hour electrocardiography based on accepted criteria ${ }^{17}$ was highest in the placebo group even when sudden cardiac death in the absence of proarrhythmia based on 24-hour electrocardiography was also regarded as proarrhythmia.

When the clinical situation permitted, follow-up exercise testing was performed in patients in whom pimobendan had been discontinued. This allowed for the ranking of patients based on exercise capacity at 24 weeks and on intervening clinical events as shown in figure (B). We believe this to be an important additional evaluation of the efficacy of chronic heart failure treatment. Effects on clinical outcome may either dilute or enhance effects on exercise capacity. ${ }^{26}$ In the present case, the trend towards a higher mortality in patients started on pimobendan raises the question whether the benefit related to the positive effect of pimobendan on exercise capacity in the survivors is negated by the higher mortality risk associated with this treatment. The ranking in figure (B) shows that patients started on pimobendan have a higher chance of surviving 24 weeks and improving their exercise capacity than patients started on placebo. The difference was, however, not statistically significant. The major limitation of this trial is therefore that it does not allow a definitive conclusion about the benefit:risk ratio of treatment with pimobendan and it is this benefit:risk ratio which would merit further study in a larger trial.

To collect further data on the safety of pimobendan, all patients were followed until a common stopping date after they completed the 24-week efficacy phase, and those who consented were kept on medication. This design feature optimises the number of patient-years of follow up which can be accumulated within a given time. Hence it was possible to evaluate mortality and the combined rate of death or first hospital admission for cardiovascular reasons over a mean follow up 
of 11 months based on intention-to-treat. Even though the differences were not significant, the hazards of both events were higher in the pimobendan than in the placebo groups (table 5). This was largely due to an increased incidence of sudden cardiac death, in particular in the pimobendan $2.5 \mathrm{mg} /$ day group. The results of Cox multivariate proportional hazard analysis showed that these differences are unlikely to be related to imbalance between treatment groups in important predictors of clinical outcome.

Because of its different mechanism of action, ${ }^{9}$ the trend towards a higher mortality in patients treated with pimobendan in this trial is unexpected despite earlier findings with predominantly cyclic adenosine monophosphate dependent phosphodiesterase inhibitors such as milrinone and enoximone. ${ }^{67}$ Our findings may be attributable to chance because the trend observed was not statistically significant. Another potential explanation is a hitherto unknown interaction between digitalis and a positive inotropic compound such as pimobendan. The excess mortality in the pimobendan groups in this trial occurred predominantly in patients who were also on digitalis at entry. Thirty five of the 47 deaths observed (table 5) occurred in patients on digitalis at entry, divided as follows over the treatment groups: eight placebo, 15 pimobendan $2.5 \mathrm{mg} /$ day, and 12 pimobendan $5 \mathrm{mg} /$ day. The corresponding numbers of deaths among patients not on digitalis at entry were three, five, and four respectively. The number of events in each subgroup was small: this subgroup analysis had not been specified in advance and the apparent interaction between the effect of pimobendan on mortality and the use of digitalis at entry was not statistically significant. Nevertheless, our data raise the question whether the benefit:risk ratio of treating heart failure patients with positive inotropic agents depends on co-treatment with digitalis. Theoretically, calcium sensitisation enhances the effects of digitalis, which acts by increasing the ionised calcium concentration within the myocardial cell. ${ }^{27}$ Possibly, this leads to overstimulation. Rather than being dependent on co-treatment with digitalis, the benefit:risk ratio may also depend on the prognosis in general. In this trial, patients on digitalis were sicker (as evidenced by lower ejection fractions) and had a worse prognosis than patients not on digitalis. In any case, these potential sources of effect modification of pimobendan, and possibly of other positive inotropic agents, warrant further investigation. The extent to which such questions can be answered in placebo controlled trials will depend to a large extent on the outcome of the currently ongoing large-scale digitalis trial.

In conclusion, as regards exercise capacity this trial confirmed the efficacy of the addition of pimobendan to the basic regimen of patients with chronic heart failure. The effect of pimobendan as monotherapy has not been studied in controlled trials thus far. Pimobendan was well-tolerated and clinically relevant proarrhythmia was not observed.
There was a trend towards an improved clinical condition in patients treated with pimobendan, but also towards a higher mortality. Hence, the balance between benefit and risk, which may depend also on concomitant use of digitalis, remains to be established.

\section{Appendix}

The Pimobendan in Congestive Heart Failure (PICO) Investigators consisted of:

CLINICAL INVESTIGATORS

Belgium: G Heyndrickx (O-L Vrouwziekenhuis, Aalst), M Renard (ULB Hopital Erasme, Brussels). Germany: S Beil, W Doering (Städt. Krankenhaus MünchenSchwabing); E Kauder (Kreiskrankenhaus Tuttlingen), H Klepzig, C Schacherer (Klinikum der Johann Wolfgang Goethe-Universität, Frankfurt), M Haass, C Krüger (Abt Innere Medizin III, Universitätsklinikum Heidelberg), P Limbourg (Stadtkrankenhaus Worms), E Liomin (Städt. Krankenhaus Singen), B. Maisch (Klinikum der Philipps-Universität, Marburg), M Schartl (Universitätsklinikum Rudolf Virchow, Berlin), H Simon (Städt. Krankenhaus Düren). The Netherlands (*member of Working Group on Cardiovascular Research): PJLM Bernink ${ }^{\star}$ (Martini Ziekenhuis, Groningen), PhW Fels* (Drechtsteden Ziekenhuis, Dordrecht), HJM Dohmen * (Groot Ziekengasthuis, Den Bosch), PHIM Dunselman*, MRP Baselier (Ignatius Ziekenhuis, Breda), NJ Holwerda* (St Elisabeth Ziekenhuis, Tilburg), GJ Laarman* (O-L Vrouwe Gasthuis, Amsterdam), CM Leenders (Havenziekenhuis, Rotterdam), $\mathrm{K}$ van Leeuwen ${ }^{\star}$ (Ziekenhuis Overvecht, Utrecht), HR Michels* (Catharina Ziekenhuis, Eindhoven), $M$ van der Ent, WJ Remme (Sticares Cardiovascular Research Foundation, Rotterdam); AJAM Withagen* (R de Graaf Gasthuis, Delft). Norway: T Gundersen (AustAgder Central Hospital, Arendal), JE Otterstad, G Frøland (Vestfold Sentralsykehus, Toensberg), TR Pedersen (Aker Sykehus, Oslo). Portugal: JR.G Ferreira, E Prazeres de Sá (Hospital de Santa Maria, Lisbon), R Seabra-Gomes, V Gil (Hospital Santa Cruz, Carnaxide). Sweden: N-J Abdon (Uddevalla Hospital, Uddevalla), J Jonsson (Varberg Hospital, Varberg).

STEERING COMMITTEE

H Just, chairman (Freiburg, Germany). ÅC Hjalmarsson (Gothenburg, Sweden), WJ Remme (Rotterdam, The Netherlands).

DATA MONITORING AND ETHICAL REVIEW COMMITTEE SJ Pocock (London School of Hygiene and Tropical Medicine, UK), T Meinertz (Universitäts-krankenhaus Eppendorf, Hamburg, Germany).

CO-ORDINATING CENTRE, CORE LABORATORY FOR ECHOCARDIOGRAPHY AND 24 HOUR ELECTROCARDIOGRAPHY AND ON-SITE MONITORING Sociéte pour la Recherche Cardiologique (SOCAR) SA, Givrins, Switzerland (FJ van Dalen, J-M Dumont, P Jonkers, BA Kirwan, D La Framboise, L Le Roux, J Lubsen; M-J Roulin, M St John Sutton; D Sekarski, A Sublet, X-F Suckow)

SPONSOR

Boehringer Ingelheim Deutschland $\mathrm{GmbH}$ (M Haehl; J Heinrich-Nols)

REPORT PREPARED BY:

J Lubsen, H Just, ÅC Hjalmarsson, D La Framboise, WJ Remme, J Heinrich-Nols, J-M Dumont, P Seed (London School of Hygiene and Tropical Medicine, UK), X-F Suckow.

\footnotetext{
1 Packer M. Treatment of chronic heart failure. Lancet 1992;340:92-5.

Kulka PJ, Tryba $M$. Inotropic support of the critically ill patient. A review of the agents. Drugs 1993;45:654-67.
} 3 scholz H, Meyer W. Phosphodiesterase-inhibiting pro- 
perties of newer inotropic agents. Circulation 1986;73: III-99-108.

4 Colucci WS, Wright RF, Braunwald E. New positive inotropic agents in the treatment of congestive heart failure. N Engl F Med 1986;314:349-58.

5 The xamoterol in severe heart failure study group. Xamoterol in severe heart failure. Lancet 1990;336:1-6 [Erratum, Lancet 1990;336:698].

6 Uretsky BF, Jessup M, Konstam MA, Dec GW, Leier CV, Benotti J, et al. Multicenter trial of oral enoximone in patients with moderate to moderately severe congestive part failure. Lack of benefit compared with placebo. heart failure. Lack of bene

7 Packer M, Carver JR, Rodeheffer RJ, Ivanhoe RJ, DiBianco R, Zeldis SM, et al for the PROMISE Study Research Group. Effect of oral milrinone chronic heart failure. N Engl f Med 1991;325:1468-75.

8 Hagemeijer F. Calcium sensitization with pimobendan pharmacology, haemodynamic improvement, and sudden death in patients with chronic congestive heart failure. Eur Heart $\mathcal{F}$ 1993;14:551-66.

9 Hasenfuss G, Holubarsch C, Heiss W, Just $H$. Influence of UDCG-115 on hemodynamics and myocardial energetics in patients with idiopathic dilated cardiomyopathy Am Heart 7 1989;118:512-9.

10 Katz SD, Kubo SH, Jessup M, Brozena S, Troha JM, Wahl $\mathrm{J}$, et al. A multicenter, randomized, double-blind, placebo-controlled trial of pimobendan, a new cardiotonic and vasodilator agent, in patients with severe congestive heart failure. Am Heart f 1992;123:95-103.

11 Kubo SH, Gollub S, Bourge R, Rahko P, Cobb F, Jessup $M$, et al for the Pimobendan Multicenter Research $M$, et al for the Pimobendan Multicenter Research Group. Beneficial erance and quality of life in patients with heart failure

2 Sasayama S, Asanoi H, Kihara Y, Yokawa S, Terada Y, Yoshida S, et al. Clinical effects of long-term administratoshida $S$, et al. Clinical effects of long-term administration of pimobendan in patients with mode

13 Remme WJ, Krayenbühl HP, Baumann G, Frick MH Haehl M, Nehmiz G, et al for the Pimobendan-Enalapri Study Group. Long-term efficacy and safety of pimoben dan in moderate heart failure. A double-blind parallel 6 month comparison with enalapril. Eur Heart $f$ 1994; 15:947-56.
14 Bazett HC. An analysis of the time-relations of electrocardiograms. Heart 1920;7:353-8.

15 The Criteria Committee of the New York Heart Association. Nomenclature and criteria for diagnosis of diseases of the heart and great vessels. 9th ed. Boston: Little, Brown;1994:253-6.

16 Rector TS, Kubo SH, Cohn JN. Patient's self-assessmen of their congestive heart failure: Part 2. Content, reliability and validity of a new measure, the Minnesota Living with Heart Failure Questionnaire. Heart Failure 1987;3: 198-209.

17 Morganroth J, Borland M, Chao G. Application of a frequency definition of ventricular proarrhythmia. $A m \mathcal{f}$

18 Myerburg RJ, Castellanos A. Cardiac arrest and sudden cardiac death. In: Braunwald E, ed. Heart disease. A textbook of cardiovascular medicine. 4th ed. Philadelphia: WB Saunders, 1992:756-89.

19 Cleland JGF, Erhardt L, Hall AS, Winter C, Ball SG on behalf of the AIRE Study Investigators. Validation of primary and secondary outcomes and classification of mode of death among patients with clinical evidence of heart failure after a myocardial infarction: a report from the Acute Infarction Ramipril Efficacy (AIRE) Study Investigators. 7 Cardiovasc Pharmacol 1993;22 (suppl 9): S22-7.

20 Declaration of Helsinki. The World Medical Assembly, Inc. Ferney-Voltaire, France, September 1989.

21 Pearson ES, Hartley HO. Charts of the power function for analysis of variance tests derived from the non-Central F-distribution. Biometrika 1951;38:112-30.

22 Armitage P, Berry G. Statistical methods in medical research. 3rd ed. London: Blackwell, 1994:207-32.

23 Rothman KJ. Modern epidemiology. Boston: Little, Brown, 1986:170-1.

24 Armitage P, Berry G. Statistical methods in medical research. 3rd ed . Bndon: Blackwell, 1994:484-7.

25 Narang $R$, Swedberg $K$, Cleland JGF. What is the ideal study design for evaluation of treatment for heart failure? Insights from trials assessing the effect of ACE inhibitor on exercise capacity. Eur Heart f 1996;17:120-34.

26 Lubsen J. Exercise testing as outcome in congestive hear failure trials. Drugs 1994;7(suppl 4):25-30.

27 Feldman AM. Classification of positive inotropic agents. $f$ Am Coll Cardiol 1993;22:1223-7. 